\title{
Disease distribution of synovial fluid mast cells and言 cytophagocytic mononuclear cells in inflammatory arthritis
}

\author{
A J FREEMONT AND J DENTON
}

From the Departments of Rheumatology and Pathology, University of Manchester Medical School, Stopford $\overrightarrow{\vec{\omega}}$ Building, Oxford Road, Manchester M13 9PT

SUMmaRY Three hundred and twenty-one synovial fluids from the knees of patients with six different inflammatory arthropathies have been examined for the presence of cytophagocytic $\omega$ monocytes (CPM) and mast cells. Both cell types were seen independently in many of the fluids $\vec{N}$ examined but were found together only in those patients with Reiter's disease, psoriatic arthritis, 을 ankylosing spondylitis, and enteropathic arthritis. These four disease groups also contain the $\vec{z}$ highest proportion of patients with mast cells in their synovial fluids and those individuals with the greatest number of synovial fluid CPM. Criteria have been developed from these observations which may be employed in the differential diagnosis of inflammatory arthropathies.

Microscopic inspection of synovial fluid is of considerable value in confirming the diagnosis of infective or crystal-induced synovitis. It is also of some use in differentiating certain other arthropathies, but its usefulness is restricted by the limited cellular response to intra-articular disease. When the proportions of the various cell types commonly seen in synovial fluids are analysed few diagnostic patterns emerge. ${ }^{1}$ Almost all synovial fluids from diseased joints fit one of four patterns: ${ }^{2}$ (a) noninflammatory (e.g. osteoarthrosis); (b) inflammatory, non-purulent (e.g. rheumatoid disease); (c) purulent (e.g. bacterial infection); and (d) haemorrhagic (e.g. pigmented villonodular synovitis) - but within each group it is usually impossible to tell diseases apart. This classification of joint disease often proves inadequate, especially in rheumatological practice where more specific intragroup diagnoses are usually being sought. In this context there is a particular need for methods to differentiate disorders in the inflammatory, non-purulent group. We describe here how the examination of synovial fluid for the presence of mast cells and cytophagocytic mononuclear cells might usefully be applied to this problem.

\section{Materials and methods}

Three hundred and twenty-one synovial fluids from Accepted for publication 3 December 1984. Correspondence to Dr A J Freemont. the knees of 316 patients have been examined. Only patients with 'firm' diagnoses based on clinical, serological, radiographic and/or pathological criteria were included. Ninety-seven fluids came from pa- $\mathbb{Q}$ tients with seropositive rheumatoid disease all of $\overrightarrow{\vec{P}}$ whom had at least five of the American Rheumatism $\frac{3}{3}$ Association (ARA) criteria for rheumatoid arthritis; 36 from patients with a seronegative erosive arthritiso which, because it also fulfilled at least five of the ARA criteria, has been termed seronegative rheumatoid disease; 51 with ankylosing spondylitis (AS) all of whom were HLA-B27 positive and had evidence of sacroiliitis or syndesmophyte formation, $\delta$ or both; six with clinical stigmata of systemic lupus erythematosus (SLE) and antibodies to double $\frac{\text { ? }}{3}$ stranded DNA in the serum; five with arthritis and $>$ either Crohn's disease or ulcerative colitis; 42 with을 psoriasis and an associated asymmetrical peripheral N arthritis; 49 with Reiter's disease, diagnosed on the basis of a combination of urethritis, conjuctivitis, $N$ and arthritis; and 34 from patients with crystals in their joints (21 with gout and 13 with pyrophosphate arthropathies).

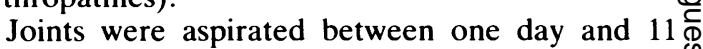
weeks (mean 3.2 weeks) from the onset of local $\stackrel{?}{+}$ symptoms and signs. The patients were not matched $\frac{T}{0}$ for age, sex, or therapy.

Synovial fluids were examined within 16 hours of $\stackrel{\mathbb{D}}{\mathscr{D}}$ removal (all fluids not processed within two hours $\stackrel{\square}{\varrho}$ were stored at $4^{\circ} \mathrm{C}$ ). Cell monolayers prepared by으 cytocentrifugation in a standard way were fixed in 


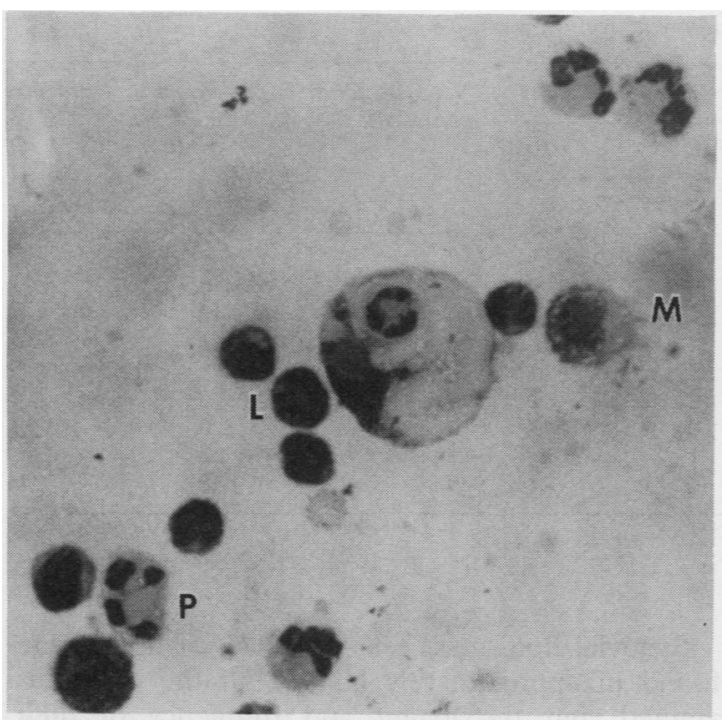

Fig. 1 A polymorph (recognisable by its characteristic nuclear morphology) is present within the cytoplasm of a large mononuclear cell. Small mononuclear cells $(M)$, lymphocytes $(L)$, and non-engulfed polymorphs $(P)$ are also seen. (Jenner-Giemsa stain, $\times 360$ ).

methanol, stained using a conventional JennerGiemsa method, and mounted in a synthetic mounting medium.

All fluids were assessed without the clinical diagnosis being known.

Cytospin preparations were examined at a magnification of $\times 700$. A differential white cell count was performed on the first 500 cells encountered and the proportion of polymorphonuclear leucocytes (neutrophils), small lymphocytes, and other mono- nuclear cells (MNC) recorded (Fig. 1). The preparations were then re-examined and the number of MNC containing included neutrophils or neutrophil nuclei (cytophagocytic mononuclear cells) noted as a proportion of the first 500 MNC encountered. Finally the cytospin preparations were scanned for the presence of mast cells which were characterised by their single round nucleus and purple cytoplasmic granules. (After methanol fixation only the cytoplasmic granules of mast cells give a purple reaction with this stain. ${ }^{3}$ )

\section{Results}

The total number of synovial fluid white cells and the proportions of polymorphonuclear leucocytes, small lymphocytes, and MNC are summarised in Table 1 . These findings are not new, being similar to those reported by others, ${ }^{14}$ but they emphasise the overlap of results which has prevented differentiation of the various diseases using routine cytology.

\section{MAST CELLS}

Most cytospin preparations did not contain mast cells and in those that did the number was usually small (between two and 10 mast cells per slide). In only nine fluids (two from patients with Reiter's disease, two with AS, three with psoriatic arthritis, one with seronegative rheumatoid disease, and one with enteropathic arthritis) did their number exceed 100 per slide. In one of these (from a patient with psoriatic arthritis) the proportion of mast cells was such $(11 \%)$ that it was recorded in the routine differential cell count. The number of mast cells was otherwise so small when compared with the total number of cells in each cytospin preparation that comparative quantification would not have yielded meaningful results, therefore only the presence or

Table 1 The proportions of the commonly occurring cell types in the synovial fluid showing the overlap between the various diseases

\begin{tabular}{|c|c|c|c|c|c|c|c|c|c|}
\hline \multirow{2}{*}{$\begin{array}{l}\text { Diseases } \\
\text { Seropositive RA }\end{array}$} & \multirow{2}{*}{$\begin{array}{l}\text { No. of } \\
\text { fluids } \\
97\end{array}$} & \multicolumn{2}{|c|}{$\begin{array}{l}\text { Total leucocyte* } \\
\text { count } \\
\times 10^{-9} / l\end{array}$} & \multicolumn{2}{|c|}{$\begin{array}{l}\text { Polymorphs* } \\
(\%)\end{array}$} & \multicolumn{2}{|c|}{$\begin{array}{l}\text { Small lymphocytes* } \\
(\%)\end{array}$} & \multirow{2}{*}{$\begin{array}{l}\text { Other } \\
\text { cells } \\
(\%)\end{array}$} & \multirow{2}{*}{$\frac{\text { mononuclear* }^{*}}{10}$} \\
\hline & & 14 & 11 & 66 & 25 & 19 & 14 & & \\
\hline Seronegative RA & 37 & 13 & 9 & 67 & 30 & 16 & 21 & 17 & 15 \\
\hline AS & 51 & 8 & 5 & 56 & 21 & 19 & 13 & 25 & 18 \\
\hline Reiter's disease & 49 & 16 & 12 & 72 & 20 & 16 & 13 & 12 & 12 \\
\hline Psoriatic arthritis & 42 & 13 & 12 & 72 & 24 & 14 & 13 & 14 & 15 \\
\hline Gout & 42 & 16 & 19 & 68 & 19 & 3 & 4 & 29 & 20 \\
\hline SLE & 6 & 12 & 13 & 55 & 33 & 24 & 24 & 21 & 20 \\
\hline Enteropathic arthritis & 5 & 10 & 9 & 54 & 46 & 20 & 19 & 26 & 30 \\
\hline Pyrophosphate arthritis & 14 & 11 & 16 & 73 & 61 & 17 & 18 & 13 & 15 \\
\hline
\end{tabular}

${ }^{*}$ Results are means and one SD. 
Table 2 The disease distribution of mast cells and cytophagocytic monocytes

\begin{tabular}{|c|c|c|c|c|c|c|c|c|}
\hline \multirow[t]{3}{*}{ Disease } & \multirow{3}{*}{$\begin{array}{l}\text { No. of } \\
\text { fluids }\end{array}$} & \multirow{3}{*}{$\begin{array}{l}\text { No. containing } \\
\text { mast cells }\end{array}$} & \multicolumn{4}{|c|}{ No. containing $C P M$} & \multirow{3}{*}{$\begin{array}{l}\text { No. with } C P M \text { and } \\
\text { mast cells }\end{array}$} & \multirow{3}{*}{$\begin{array}{l}\text { No. with CPM ar } \\
\text { mast cells } \\
\text { or } 10 \%+C P M\end{array}$} \\
\hline & & & \multicolumn{3}{|c|}{$\% C P M$} & \multirow[t]{2}{*}{ Total } & & \\
\hline & & & $1-5$ & $6-10$ & $10+$ & & & \\
\hline Seropositive RA & 97 & 2 & 14 & 3 & 0 & 17 & 0 & 0 \\
\hline Seronegative RA & 37 & 4 & 3 & 0 & 0 & 3 & 0 & 0 \\
\hline AS & 51 & 22 & 13 & 2 & 4 & 19 & 10 & 12 \\
\hline Reiter's disease & 49 & 20 & 16 & 4 & 13 & 33 & 13 & 21 \\
\hline Psoriatic arthritis & 42 & 14 & 6 & 5 & 5 & 16 & 6 & 9 \\
\hline Gout & 21 & 1 & 2 & 2 & 0 & 4 & 0 & 0 \\
\hline SLE & 6 & 0 & 3 & 0 & 0 & 3 & 0 & 0 \\
\hline Enteropathic arthritis & 5 & 2 & 0 & 1 & 1 & 2 & 1 & 2 \\
\hline Pyrophosphate arthritis & 13 & 0 & 2 & 1 & 0 & 3 & 0 & 0 \\
\hline
\end{tabular}

absence of mast cells has been recorded (Table 2). Mast cells were found in between a third and a half of synovial fluids from patients with AS, Reiter's disease, psoriatic arthritis, and enteropathic arthritis, but rarely in fluids from patients with rheumatoid disease, crystal arthritis, and SLE.

\section{CYTOPHAGOCYTIC MONONUCLEAR CELLS}

CPM were found in all the diseases studied. However, fluids containing the higher proportions of CPM came from a more limited group of diseases (Table 2). Those fluids in which more than $10 \%$ of the MNC were cytophagocytic came exclusively from patients with AS, Reiter's disease, enteropathic arthritis, and psoriatic arthritis. Mast cells and CPM were found together only in fluids from patients with these same four diagnoses (Table 2). Forty-four of 147 patients with AS, Reiter's disease, psoriatic arthritis, and enteropathic arthritis had either more than $10 \%$ CPM or both CPM and mast cells in their synovial fluids.

\section{Discussion}

With the exception of septic and crystal arthritis synovial fluid examination has proved unhelpful in the differential diagnosis of inflammatory joint disease. This is largely because no known synovial fluid cell-type is specific for any one disease and the proportions of recognisable cells are very similar in all the disorders. In an effort to increase the usefulness of the cytological examination of synovial fluid we have studied two of the less frequently encountered cell types.

To our knowledge these are the first reports of the disease distribution of synovial fluid mast cells and the quantification of cytophagocytic mononuclear cells in a large number of cases of inflammatory arthritis.
Synovial fluid mast cells or CPM, or both, wereㅇำ found in approximately half of all the cases examined, but the extent and frequency of their occurrence varied between diseases and between individuals in any one disease group. Proportionally $\vec{\infty}$ more synovial fluids from patients with AS, Reiter'ș disease, enteropathic arthritis, and psoriatic arthritis contained CPM and mast cells than those from patients with the other diseases in this study. In addition those cases with the highest numbers of CPM also came from these four disease groups. $\mathbb{D}$ Thus all of the cases containing more than $10 \%$ CPM or both CPM and mast cells, $90 \%$ with mast cells alone and $66 \%$ with between $6 \%$ and $10 \%$ 工 CPM had AS, Reiter's disease, psoriatic arthritis, of enteropathic arthritis clinically. None of the criteria was able to distinguish between these four arthro-a pathies.

The mechanisms controlling the accumulation of mast cells in synovial fluid are unknown. It iso possible that they may represent 'overspill' from the 3 synovium, but the only adult human inflammatoryo arthropathy in which the synovial mast cell content has been closely studied is rheumatoid disease. ${ }^{5}$ In? rheumatoid synovium and elsewhere, mast cells have been implicated in connective tissue degradation. ${ }^{56}$ This process is mediated, in part, by histamine, of which they are the major source. High levels of histamine have been recorded in theo synovial fluid of patients with rheumatoid arthritis, but we have been able to identify mast cells in the synovial fluid of only a small proportion of patients with rheumatoid disease. As the recognition of masto cells depends on the characteristic reaction of theiro cytoplasmic granules, it is conceivable that both their apparent absence and raised synovial fluid $\vec{D}$ histamine may be explained by mast cell degranulation in the fluid. 
Neither the exact nature nor pathogenic significance of CPM is known. Spriggs et al. ${ }^{7}$ in their study of Reiter's disease were unable to relate the presence of CPM to any clinical manifestation of the disease, and we can find no apparent relationship between CPM and the progression or duration of any single disorder. However, the proportion of MNC showing phagocytosis does vary between clinically defined groups. Patients with the highest numbers of CPM came from the four groups (i.e. those with arthritis associated with AS, Reiter's disease, psoriasis, and inflammatory bowel disease) that also contained the greatest proportion of patients with synovial fluid mast cells. Whether the variation in synovial fluid cytology reflects differences in the underlying pathogenic mechanisms in synovial inflammation in the inflammatory arthropathies is beyond the scope of this study, but we have exploited these observations to develop criteria which could be applied as a simple screening test whenever the clinical presentation of a patient raises the possibility of one of these four disorders.

This work was funded by the Arthritis and Rheumatism Council. We are grateful to Professor J Ball for his advice and guidance. and to the John Charnley Trust for providing the microscope used in this study.

\section{References}

1 Revell P A. Examination of synovial fluid. Curr Top Pathol 1982; 71: 1-24.

2 McCarty D J. Synovial fluid. In: McCarty D J, ed. Arthritis and allied conditions: a text book of rheumatology. Philadelphia: Lea and Febiger, 1979: 51-69.

3 McDonald D J, Dodds T C. Cruickshank B. Atlas of haematology. Edinburgh \& London: Churchill Livingstone, 1968: 9.

4 Currey H L F, Vernon-Roberts B. Examination of synovial fluid. Clin Rheum Dis 1976: 2: 149-77.

5 Crisp A J. Mast cells in rheumatoid arthritis. J R Soc Med 1984: 77: 450-1.

6 Bromley M. Fisher W D. Wooley D E. Mast cells in sites of cartilage erosion in the rheumatoid joint. Ann Rheum Dis 1984; 43: 76-9.

7 Spriggs A I, Boddington M M. Mowat A G. Joint fluid cytology in Reiter's disease. Ann Rheum Dis 1978; 37: 557-60. 